\title{
Learning Chinese as the United Nations Language? Implications for Language Learning Motivation and Identity in Adult Higher Education
}

\author{
Hugo Yu-Hsiu Lee ${ }^{1}$ \\ ${ }^{1}$ Associate Professor of Sociolinguistics, National Institute of Development Administration (Thailand), Consultant, \\ United Nations (Economic and Social Commission for Asia and the Pacific, Bangkok) \\ Correspondence: Dr. Hugo Yu-Hsiu Lee, National Institute of Development Administration, 118 Moo 3, Serithai \\ Road, Klong-Chan, Bangkapi, Bangkok Thailand 10240. E-mail: hugoclubheart3@gmail.com
}

Received: October 30, 2019

Accepted: December 6, 2019

Online Published: December 11, 2019

doi:10.5430/ijhe.v9n1p168

URL: https://doi.org/10.5430/ijhe.v9n1p168

\begin{abstract}
In this study, the researcher strives to build on earlier work in which the roles of motivation and identity in language learning in adult higher education were examined. In the present connection, the focus falls on the roles played by a seldom researched group consisting of staff members in an intergovernmental organization. This group is comprised of United Nations staff members ( $\mathrm{N}=33 / 18$ female, 15 male) involved with the United Nations Chinese language program at the UN Headquarter for the Asia region in Bangkok. The past research has shown that an adult language learner's learning level becomes very high when s/he is sufficiently motivated. In this light, then, the researcher explores whether the language-learning process would be improved if adult staff members from an intergovernmental organization engage in language learning with a greater sense of a professional self/institutional identity than would be the case with a merely personal identity. Also considered is whether the language-learning process is enhanced by an individual/personal identity in contrast to having only a professional self/institutional identity. The findings show that UN staff members who are highly motivated to learn Chinese are more likely to harbor a mixture of both personal and professional identities. Nevertheless, prioritizing the learning of Chinese often stems from functional and practical reasons, i.e., from instrumental motivation. Finally, this study finds no clear links between Chinese heritage and success in Chinese language learning in the adult higher educational sector.
\end{abstract}

Keywords: language learning motivation, language learning identity, Chinese Mandarin, adult education, the United Nations

\section{Introduction}

Over the past 30 years, a significant number of applied foreign/second language teaching/learning researchers have contributed to a growing body of applied language teaching/learning literature (e.g., Lee, 2013, 2014, 2016, 2018; Kim, 2018; Cho, 2018, to name only a few). Most studies of applied foreign/second language teaching/learning primarily focus on formal and informal educational settings. However, only a paucity of research has been conducted in an intergovernmental organizational context where a language is taught and learned by adult learners as an institutional language.

In recent years, language learning motivations and language learning identities have been the focus of attention in applied linguistics and language education. Motivation and identity are identified and discussed frequently in the academic literature on teaching/learning English as a foreign/second language. However, as we know from the available literature on teaching/learning Chinese as a foreign/second language, very little research has been devoted to the language as an intra-organizational institutional language.

To address the aforementioned two lacunae in the literature of foreign/second language teaching/learning and research, the present study examines factors that influence learning Chinese (Mandarin) as a United Nations' institutional (official) language by its staff members with a particular emphasis on the effects of motivation and identity on their Chinese language learning. Firstly, instead of focusing on traditional research sites - such as formal and non-formal learning spaces-the present study seizes the opportunity to explore an institutional language's teaching, learning and concomitant research in the context of an intergovernmental organization such as the United Nations Headquarters. Secondly, the current research investigation seeks to advance Chinese language learning motivation research and Chinese language learning identity research so as to make a distinct contribution to 
foreign/second language and institutional language teaching, learning and research and to related areas of research endeavor. Accordingly, this paper examines the under-researched institutional self/organizational identity developed by staff members when acquiring a foreign/second language and/or an institutional (official) language from the context of adult education. The present paper also compares what previous research reveals about motivation and identity in applied foreign/second language teaching/learning against the backdrop of the current data-sets amassed by the researcher with a focus falling on the disparity between heritage (second-third generation ethnic Chinese/Chinese Thai) and non-heritage learners of Chinese and the learning of Chinese as a matter of personal interest or pursued for career development goals and thus for intrinsic or extrinsic motivations or even for both types of motivation.

The present study is situated within the context of learning a language as an institutional language in an organizational setting. According to Dessler (2018, p.2), "An organization consists of people with formally assigned roles who work together to achieve the organization's goals." Extrapolating from this perspective, one can add that the organizational context of a national institute or an intergovernmental organization leads to the emergence of language-use policies and language-use practices on the part of these organizations.

The Chinese language is taught, learned and used at the United Nations as an institutional language in view of the fact that it is one of the six United Nations official languages. The United Nations Secretariat (28 December 2017) has stated that six UN official languages "are offered to promote linguistic balance and multilingualism within the Secretariat and to improve the language abilities of staff, as mandated by the United Nations General Assembly in its resolutions 2480 B (XXII), 43/224 D and 50/11." United Nations staff members are thus required to learn two United Nations official languages for the sake of advancement in the United Nations system. In contrast to the organizational goals of promoting an institutional language, individual staff members of an organization will normally also have personal motivations and project individual identities as reasons for learning a foreign/second language and/or an institutional language in formal domains such as is found in the case of the United Nations Secretariat.

\section{Literature Review and Theoretical Perspectives}

This review of the literature primarily focuses on the roles of motivation and identity in foreign/second language teaching/learning and research. Studies in the field of motivation and identity in foreign/second language teaching/learning and research are concerned with the complexity of the interdisciplinary nature of the language learning processes engaged in by learners from different backgrounds and across a variety of contexts.

Three bodies of literature concerning applied foreign/second language learning are explored, largely because they provide the relevant theoretical framework for the current study:

1) Motivation in applied foreign/second language teaching, learning and research

2) Identity in applied foreign/second language teaching, learning and research

3) Communication and culture in applied foreign/second language teaching, learning and research

(Learning a language of communication versus learning a language of culture)

\subsection{Language Learning Motivation}

There are references to previous research and theories in regard to motivation in applied foreign/second language teaching, learning and research. In regard to motivation, Dörnyei $(2002$, p. 8) has very aptly epitomized motivation as appertaining to "why people decide to do something, how long they are willing to sustain the activity and how hard they are going to pursue it" (bolding elided). With this perspective in view, it should be pointed out that researchers in the field of language learning motivation strive to grasp why language learners are interested in learning a target language and what meaningful connections are found between the target language they learn and the lives they live.

In the course of propagating one of the most influential language learning theories, Gardner (1985) has suggested two categories of motivations. Integrative motivation, as defined by Gardner (1985), refers to a person's desire to learn a target language in order to identify with the members of the community who speaks the target language, thereby revealing a desire to assimilate or integrate with speakers of the target language. By way of contrast, instrumental motivation refers to a language learner's desire to learn a target language in order to meet his or her needs and/or goals for practical reasons such as better employment opportunities or a salary increase and so forth (Mackey, 2014).

It can thus be inferred that people who are motivated extrinsically are similar to those who are motivated 
instrumentally. This in turn means that extrinsically motivated language learners are those who are driven by external rewards to learn a foreign/second language or an institutional language.

As opposed to extrinsic motivations, Mackey (2014) recognizes that some heritage learners are intrinsically motivated to learn Chinese, so that, for instance, they are able to communicate with family members and relatives. Other people with intrinsic motivations to learn Chinese also include those who are genuinely interested in Chinese cultures (Mackey, 2014).

\subsection{Language Learning Identity}

There are previous scholarly works conducted in the field of identity in applied foreign/second language teaching, learning and research. We find that there is a well-developed line of discussion and nowadays an increasing interest in language and identity research in applied linguistics and language education. The organizing committee's view as stated in the Eighth Center for Language Studies International Conference brochure is that "identity refers to the dynamic representations of self that a language learner adopts, constructs, maintains or negotiates in relation to his social, cultural and political contexts" (National University of Singapore, 2018, p. 2).

As Norton (1995, 2013) and Block (2007) point out, scholars of foreign/second language recognize that language and identity tend to concur in the view that not only do language and identity closely influence one another, but that they are also strongly interconnected with one another. As language learners acquire a foreign/second language or an institutional language, they additionally became conscious of what they have become as individuated self-conscious selves through the development and maintenance of a newly acquired second/foreign language "self."

However, it is extremely significant that language and identity research applying ethnic identity theories to study the field of maintenance and shifts from an ethnic language generally suggest that speaking an ethnic language does not in itself guarantee an ethnic identity for an ethnic minority group. According to Sankar (2011), a very small percentage of ethnic Tamil speakers link their ability to speak Tamil to their ethnic identity as Malaysian lyres in Malaysia. Sankar's study shows that identity is not dependent on an ethnic minority group's ethnic language. To the contrary, in cases such as these, ethnic identity is much more frequently expressed through cultural practices. Furthermore, these studies also show that if the ethnic language is not spoken in the home domain, the members of the ethnic group experience a distancing from their ethnic identity (David, Dealwis \& Alagappar, 2011).

While there are references (cited in this review section) to previous studies and theories in the field of motivation and identity and their implications to applied linguistics research, language teaching and language learning in general, more in-depth analyses of prior research are available in Dörnyei (2002), Gardner (1985) and Mackey (2014), among others, for readers to fully grasp the relevance to the current study. Moreover, please consult with previous research undertaken particularly by Dörnyei and Gardner for the general field of language learning motivation and language learning identity.

After reviewing these above-mentioned two bodies of literature, let's now turn to contributions of the current study to the language, motivation and identity literature. Firstly, the present study represents a shift away from investigating conventional educational settings (such as formal classrooms) towards inquiring into non-educational and organizational settings. Secondly, by focusing on motivation and identity in the field of Chinese language teaching, learning and research in a formal domain, the present study constitutes a shift in the field from focusing on traditional English-language teaching, learning and research towards a foreign/second language and/or an institutional language other than English. Thirdly, moreover, this paper represents a shift from individualized foreign/second language learner's motivation and identity studies towards research on institutional language learners' motivation and identity in view of adult education.

\subsection{Language Learning for Communication versus Language Learning of Culture}

In addition to motivation and identity, the third section added to the literature review is two parallel strands of research, considering the place of communication in language learning as contrasted to learning a language of culture. The first strand identifies communication as both the main purpose and the essential result of language learning. While there is an abundance of literature, please see some prior studies in this strand stressing communication in language learning, including Richard, (1976), Wylie (1985), Seven (2007) and Ibsen-Jensen, Tkadlec, Chatterjee and Nowak (2018). The first strand of studies suggests that teaching and learning a language is aimed for communicative competence among language learners. The second strand of studies recognizes that target language cultures have become indispensable for language learners while learning a foreign/second language, largely because a language cannot be learned without taking into account the cultural context, particularly the culture of the target language community in which the language is used. Many scholars hold this view and embrace cultures in 
language teaching and learning, such as Thanasoulas (2001), Genc and Bada (2005), Arabski and Wojtaszek (2011), Hinkel (2011), to name but a few. Scholars from the second strand of research contend that learning a language results in cultural transmission and there should be sufficiently an incorporation of target language cultures into foreign/second language teaching and learning.

The two parallel strands of research have not led to opposing views. The first strand of studies does not deny the importance of cultures in language learning, nor does the second strand of research abandons the role of communication in language learning.

\section{Methods}

The current study addresses two research questions: RQ1, what motivates staff members to learn Chinese as an institutional language in an intergovernmental organization? And RQ2, what do staff members of an intergovernmental organization reveal about Chinese language learning motivations in relation to their identities?

The study adopts qualitative research methods. The present study approaches its site and participants with a mixture of three field methods:

1) Action Research (Gay \& Airasian, 2003)

2) Ethnography with Participant Observation (Hymes, 1977)

3) Grounded Theory (Glaser \& Strauss, 1967)

Mixed qualitative approaches to inquiry are employed in gathering and analyzing data in lieu of taking a quantitative approach or a mixed qualitative-quantitative approach. This is largely because the researcher's central aim is to develop an in-depth understanding of the phenomenon of learning Chinese as an institutional language within the context of adult higher education rather than seeking to extrapolate trends from compiled data-sets. As such, this study adopts qualitative research conventions (Merriam, 2009) through applications of ethnography (Hymes, 1977), grounded theory (Glaser \& Strauss, 1967) and case studies (Merriam, 2009). As a qualitative action research study (Gay \& Airasian, 2003), in which the teacher (author) at the focal organization is the primary teacher, a concerted attempt is made to develop an integrated framework combining perspectives from motivation and identity studies in foreign/second language learning allowing the investigation of focal staff members who are adult learners.

To address the two research questions, the research site was the United Nations, Economic and Social Commission for Asia and the Pacific, Bangkok (UN Headquarters, Asia). Taking the United Nations, Bangkok (single site) as a paradigmatic exemplar of an intergovernmental organization, the researcher accordingly selected United Nations staff members from the United Nations Chinese language program as participants.

This study subsequently focused on the Chinese language learning practices of 33 focal middle-aged adults (40-55) and older adults (55-70) who were staff members at the site. The members of the sample, population consisted of 15 male and 18 female United Nations staff members (sample size =33). They were chosen on the basis of deploying a purposive sampling method whereby those and only those who were enrolled in the United Nations Chinese language program at the United Nations Learning Center became members of the sample population. Only 33 out of 49 staff members were at beginning levels, i.e., UN Chinese level 1-2 (UN Chinese level 2 is equivalent to standard HSK 1) at the site were included in the sample population under investigation.

It should be noted that when data were collected from August-December 2018, there was a significant number of adult Chinese language learners enrolled in intermediate-advanced levels, including nine staff members at UN Chinese level 3, 10 staff members at UN Chinese level 5 and 22 staff members at UN Chinese level 7 (UN Chinese level 7 is equivalent to standard HSK 5) at the site, but they are not included in the sample population under study (largely because they were taught by other UN Chinese teachers and cannot be invited to participate in the study by the author). Furthermore, by virtue of following a limited number $(n=14)$ of heritage (second-third generation ethnic Chinese/Chinese Thai) and non-heritage Chinese language learners ( $n=19)$ as participants $(N=33)$, this study is able to present evidence of the extent to which Chinese heritage might be effective or ineffective - as the case may be-in motivating learners from different backgrounds.

Demographic profiles (e.g., age and name) of members of the sample population are not released. However, some demographic data such as affiliations with the United Nations system are available as follows. A large majority of members of the sample population work for the United Nations Environmental Program (UNEP), the United Nations Energy Division (UNED), the United Nations Higher Commission for Refugees (UNHCR), the United Nations Department of Safety and Security, the United Nations Conference Center (UNCC) and the United Nations Children's Fund (UNICEF). In contrast, a relatively smaller number of members of the sample population are 
employed by the United Nations International Labor Organization (ILO), the United Nations Population Fund (UNFPA) and the United Nations Office for Project Services (UNOPS).

In the present study, the researcher adopted four research instruments for gathering data from the members of the sample population $(\mathrm{N}=33)$ :

1) A needs analysis for Chinese language use $(n=19)$

2) A qualitative survey with two open-ended questions

(Google Form distributed to 30 participants with 11 participants replying) $(\mathrm{n}=11)$

3) An interview topic list (semi-structured interviews) ( $n=33)$

4) A field report sheet for recording observations of participants $(n=33)$

Conducted between October-November 2018, the qualitative survey in Google Form (research instrument 2) - entitled Innovation and Identity in Learning Chinese (Mandarin) in an Intergovernmental Organizational Setting - was designed to elicit answers to the following questions as primary data: (a) what motivates you to learn Chinese (Mandarin)? Personal interests? Professional interests? Upper professional mobility in the UN system? Other reasons? and (b) what do you consider to be your identity as a Chinese language learner or Chinese language user in an organizational setting such as the UN or elsewhere (at home, say)? Have you succeeded in becoming the person you wanted to become after having acquired the Chinese language?

In sum, four research instruments were adopted-a needs analysis, a qualitative survey that elicited responses, ethnographic interviews (individual and group interviews), and observational field-notes. Consequently, four data-sets were thereby compiled and a corresponding database was constructed.

The present study adopts the procedure of data collection with four research instruments as described below. Using the four aforementioned research instruments, four different data-sets were compiled to form a database concomitant with collecting data over a two-year period (January, 2017-November, 2018). Firstly, the needs analysis for Chinese language use (research instrument 1.) was conducted verbally on 6 August 2018 with 19 participants from the sample population. The data elicited were given in hand-written form. Secondly, the qualitative survey in Google form (research instrument 2.) was distributed by email to 30 participants on 3 October 2018, followed by email reminders sent twice after 3 October 2018. Elicited were responses in typed form from 11 out of 30 participants. Thirdly, semi-structured interviews (research instrument 3) were undertaken one-on-one and as a group with members of the sample population from January 2017 to November 2018 (no interviews were conducted during December 2017 and June-July 2018 because of breaks). Fourthly, participant observations (research instrument 4) utilizing field report sheets were conducted from January 2017 to November 2018 (no observations were conducted during December 2017 and June-July 2018 because of breaks).

It should be noted that two adult members of the sample population left the site before June-July 2918 with only interview data and field-notes available to the researcher. They did not participate in the needs analysis, nor in the qualitative survey. They left to resettle to the duty stations of the United Nations, New York (UN Headquarters) and the United Nations office in Rome, Italy, respectively.

While gathering data, conceptual lenses forged in the fields of language learning motivation and language leaning identity were employed by the researcher in the course of exploring learners' activities, events, episodes, interactions and exchanges. By the same token, linking data collection to theories and theoretical frameworks as discussed in the literature review was undertaken so as to build the database. If the description of some research instruments during data collection are not sufficiently clear to some readers, please consult with the author by email or skype.

These were the methods of data analysis. Three analytical approaches were taken in analyzing the database constructed on the basis of four data-sets as follows:

1) Content Analysis

2) Grounded Theory (Glaser \& Strauss, 1967)

3) Situational Analysis (Clarke, 2005)

Accordingly, the research analysis adopted in the present study was contextualized within theoretical and empirical frameworks in the fields of language learning motivation and language learners' identities. In other words, codes and themes from the literature review were adopted in the course of carrying out qualitative data analyses. Coding schemes adopted were applied to the following codes: integrative motivation, instrumental motivation, institutional identity/organizational identity (professional identity) and individual identity/personal identity, and ethnic identity 
(Chinese heritage or non-Chinese heritage). Validity and reliability in qualitative data analysis were enhanced by participant checking (member check) or verifying the data collected by the researcher in addition to triangulating the four datasets, viz., needs analysis reports, qualitative survey responses, interviews, and ethnographic field-notes from on-site observations.

\section{Results}

These are answers to RQ1: What motivates staff members to learn Chinese as an institutional language in an intergovernmental organization? Findings from this new study's first dataset (research instrument 1.) strongly suggest that personal interests and individual goals provide greater instrumental motivations for adult language learning than do organizational goals (e.g., linguistic balance and a multilingual working environment at the United Nations Secretariat in New York). Summarily speaking, it can be concluded that learning a language (such as Chinese) as an institutional language by a staff member in a formal domain (also in an adult educational program) is not directly affected by institutional policy.

The researcher found needs analysis evidence that clearly shows that the most important motivation for Chinese language learning is to carry out everyday tasks (e.g., introducing yourself, asking for directions, asking the time, taking a taxi, ordering food and telephone conversations). By the same token, this new study demonstrates the importance of learning survival Chinese for everyday conversational tasks instead of learning Chinese for professional purposes at the United Nations (e.g., Chinese for meetings, Chinese for diplomacy and Chinese for United Nations duty missions in China).

Close to half of the participants in the qualitative survey (research instrument 2) claim that they have both personal and professional interests (e.g., career development) in a mix of reasons (both intrinsic and extrinsic) for learning Chinese. A good explanation of their Chinese language learning must balance two different motivations: (1) learning Chinese is associated with personal and practical reasons (e.g., understanding Chinese cultures vis-à-vis Chinese culinary traditions or for necessary communication during visits to China) and (2) learning Chinese for professional life - career development (e.g., communicating with Chinese colleagues in the office and in meeting rooms). By way of contrast, more than half of the participants in the qualitative survey (this new study's second dataset) state that they only have reasons of personal interest for learning Chinese. In other words, their Chinese language learning has little or nothing to do with their work at the United Nations. At least to some degree, the qualitative survey (research instrument 2) conducted in October 2018 largely echoes the findings of the needs analysis (research instrument 1) conducted two months earlier in August 2018. The difference is that nearly two-thirds of the participants in the earlier needs analysis displayed little by way of professional interest and developing an organizational self as reasons for learning Chinese. As a result, it seems that discrepancies remain between dataset 1 (needs analysis results) and dataset 2 (qualitative survey responses).

It should yet be acknowledged that a number of participants learn Chinese for practical reasons (defined as instrumental motivation), such as a salary increase or a bonus at the United Nations. This view is strongly supported by interview data.

Three female participants, who are parents, report that they learn Chinese and teach Chinese to their children, largely because their children learn Chinese in school and they strongly embrace actions on their part which assist in enabling their children to have future social and economic advantages by being able to speak Chinese.

As it turns out, the language-learning process is enhanced by motivating adult language learners to learn as suggested by the current study. In many cases, this new study has found that United Nations staff members learning Chinese do better when what is taught suits their needs rather than other motivational factors. The current research confirms earlier studies that the language learning process can be greatly improved when language learners are motivated to learn. 
Table 1. Needs for Chinese Language Use at the United Nations

\begin{tabular}{|c|c|c|}
\hline $\begin{array}{l}\text { Chinese language skills needs of } \\
\text { United Nations staff members }\end{array}$ & $\begin{array}{l}\text { Quantity of those United Nations } \\
\text { staff members whose needs } \\
\text { are served }(n=19)\end{array}$ & Rank \\
\hline $\begin{array}{c}\text { Chinese for everyday } \\
\text { conversations/survival Chinese }\end{array}$ & $\begin{array}{ll}\text { needs } & 13\end{array}$ & $\begin{array}{c}1=\text { Priority } \\
\text { (The most useful function of the } \\
\text { Chinese language) }\end{array}$ \\
\hline $\begin{array}{l}\text { (e.g., introducing oneself, } \\
\text { asking for directions, } \\
\text { asking the time, } \\
\text { taking a taxi, ordering food, } \\
\text { and telephone conversations) }\end{array}$ & & \\
\hline Chinese for business & 5 & $\begin{array}{l}\qquad 2=\text { Very Important } \\
\text { (The second most important reason } \\
\text { for learning the Chinese language) }\end{array}$ \\
\hline Chinese for diplomacy & 4 & $\begin{array}{l}\quad 3=\text { Important } \\
\text { (The third most important reason for } \\
\text { learning the Chinese language) }\end{array}$ \\
\hline $\begin{array}{l}\text { Chinese for the workplace/ office } \\
\text { (e.g., email communications, } \\
\text { face-to-face communications with } \\
\text { Chinese colleagues, guiding Chinese } \\
\text { applicants who are taking UN } \\
\text { examinations) }\end{array}$ & 3 & $\begin{array}{l}4 \\
\text { (The fourth most important reason } \\
\text { for learning the Chinese language) }\end{array}$ \\
\hline $\begin{array}{l}\text { Chinese for meetings } \\
\text { with Chinese colleagues }\end{array}$ & 3 & $\begin{array}{l}4 \\
\text { (The fourth most important reason } \\
\text { for learning the Chinese language) }\end{array}$ \\
\hline Helping children learn Chinese & 2 & $\begin{array}{l}5 \\
\text { (The second least important reason } \\
\text { for learning the Chinese language) }\end{array}$ \\
\hline Chinese for travel in China & 1 & $\begin{array}{l}\text { Not very important: } \\
\text { Does not serve the needs of } \\
\text { the majority of participants }\end{array}$ \\
\hline $\begin{array}{c}\text { For entertainment } \\
\text { (e.g., Watching Chinese television } \\
\text { series) }\end{array}$ & 1 & $\begin{array}{l}\text { Not very important: } \\
\text { Does not serve the needs of } \\
\text { the majority of participants }\end{array}$ \\
\hline $\begin{array}{l}\text { Refreshing one's memory of past } \\
\text { learning of the Chinese language }\end{array}$ & 1 & $\begin{array}{l}\text { Not very important: } \\
\text { Does not serve the needs of } \\
\text { the majority of participants }\end{array}$ \\
\hline
\end{tabular}

Sources: Dataset 1 (Needs analysis results) 
Here are answers to RQ2: What do staff members of an intergovernmental organization reveal about Chinese language learning motivations in relation to their identities? Crucially, the researcher did not find clear links between organizational goals and individual or personal goals in learning Chinese as an institutional (official) language among adult learners. That is to say, this study suggests that these results indicate that the language learning process at the individual level (personal identity) does not require an organizational goal (professional identity) for the majority of staff members. Data from the qualitative survey (research instrument 2) show that learning the Chinese language is inseparable from both personal interests (individual identity) and professional interests (organizational identity) as reported by 7 out of 11 participants (Google Form was distributed to 30 participants, with only 11 replies received by the researcher). In the same dataset, 4 participants out of 11 associate their Chinese language learning only with their personal interests (individual identity) without regard to their institutional identity. At the same time, however, 4 other participants view themselves as Chinese language learners in view of their position in the United Nations system. The researcher attributes their greater organizational identities to the prestige of being affiliated with the United Nations. Or they may exclusively associate their Chinese language learning experience with the United Nations Learning Center where they study Chinese if they do not use Chinese outside the United Nations Learning Center.

In the current study, the researcher does not find clear links between the ethnic identity of staff members and increased learning or improvement in learning the Chinese language. In general, participants with ethnic Chinese background-labeled as heritage learners - are able to learn Chinese with alacrity at a higher level than the majority of their non-heritage counterparts. However, the current study is not able to give reasons for why some particular heritage learners were found to have outperformed other heritage learners, especially in view of the fact that a small number of non-heritage learners - an Australian, a Canadian and a Netherlander - outperform some heritage learners, viz., ethnic Chinese/Chinese Thai participants. Undoubtedly, those results suggest that a language learner's ethnic identity often plays a significant role for the language-learning process for some particular learners, but does not play an important role for others.

In the present database, for example, only one of the highly skilled heritage learners - as testified to by her being able to pass Chinese quizzes and examinations with outstanding scores-learned Chinese to such a high level that she is able to understand and communicate with her relatives from China. Moreover, she is strongly motivated to learn Chinese, largely because both of her parents are first-generation Chinese immigrants to Thailand and her father writes his diary entries in Chinese. (Although she has not been asked to do so by her father, she probably wants to read her father's dairy entries written in Chinese.) The other heritage learner who did not achieve a higher level of success in learning Chinese attributes her learning the Chinese language to her Chinese family roots, claiming herself to be 25 percent Chinese. In contrast, another highly skilled heritage Chinese learner showing outstanding Chinese ability was found to have been both intrinsically and extrinsically motivated to learn Chinese, but she yet does not attribute her Chinese language learning to the fact of her Chinese heritage.

\section{Discussion and Conclusion}

\subsection{Discussion}

Based on this new research, it is unclear as to what is the role of Chinese heritage in the Chinese language learning process for both heritage and non-heritage adult learners. Some are heritage learners (referred to as ethnic Chinese / Chinese Thai), but still do not succeed in learning Chinese as compared to those who are non-heritage learners from Australia, Canada and the Netherlands. It is not surprising to see that some participants in the present study are those individuals who develop more talents to learn a foreign/second language of communication, regardless of their heritage Chinese or non-heritage Chinese background. With excellent written and spoken skills, only one of the most highly skilled Chinese language learners from the present sample population has Chinese heritage. This particular participant (female, aged $60+$ ) has learned the Chinese language at a high level of proficiency in the space of only two years of exposure in the adult educational program (UN Learning Centre) at the research site (United Nations, Bangkok duty station). Nonetheless, there are other heritage learners with very limited Chinese proficiency who are in the same class and thus study with her. Within the context of the great integration where ethnic Chinese community members (referred to as ethnic Chinese / Chinese Thai) have generally assimilated into the Thai society (please see Lee, 2014, for references to assimilation of Chinese in Thailand), it is evident that some non-heritage Chinese language learners (where Chinese is viewed as their language for communication) are outperforming some heritage Chinese language learners (where Chinese is regarded as the language of their culture). Similar to Sankar's (2011) research findings, this new study finds that some heritage learners might express their ethnic identity through cultural practices other than their ethnic language. Contrary to David, Dealwis and Alagappar 
(2011), one of the heritage learners does not experience diminished ethnic identity (25 percent Chinese heritage), simply because he cannot speak Chinese.

In this new study, the researcher has found no evidence of integrative motivation (Gardner, 1985) in which there is an expressed desire to become a member of the Chinese speaking community by participants who manage to succeed in learning Chinese, as well as those who do not achieve a high level of success in Chinese language learning. It seems, however, the majority of participants confirm that they are driven by instrumental motivations as specified by Gardner (1985) and Mackey (2014).

\subsection{Limitations}

Largely because of a small sample size, results are to be interpreted with due cautions. While there are valid implications for the United Nations as an intergovernmental organization, the general implications for the wider-reaching fields of language learning motivation and language learning identity might not be substantial.

\subsection{Concluding Remarks}

In short, the present study examines factors that influence Chinese as an institutional (official) language learning by United Nations staff members with a particular emphasis on the effects of motivation and identity on their Chinese language learning in an adult educational program (UN Learning Centre). As noted above (second dataset), United Nations staff members who are highly motivated to learn Chinese are more likely to have a mixture of both personal and professional interests in Chinese (different motivations at different times). However, prioritizing the learning of Chinese is often for functional and practical reasons (based on the first dataset), such as being able to ask for directions in China, calling someone over the telephone in Chinese, for salary increases or for the sake of bonuses and so on. Furthermore, some may want to learn Chinese to help their children learn Chinese in school. Others may learn Chinese for career advancement in the workplace and so on.

\subsection{Implications}

To explore the language learning motivations and language learning identities of staff members can be shown to be beneficial for both governmental institutions, intergovernmental organizations, not to speak of other sectors. These findings have implications on how the United Nations Secretariat, New York, views their United Nations Chinese language programs across United Nations Headquarters (global and regional) and United Nations offices (e.g., New York, Geneva, Vienna, Nairobi and Bangkok). When asked on November 2-3 2018 by the United Nations, New York (Headquarters) if staff members at the United Nations, Economic and Social Commission for Asia and the Pacific, Bangkok duty station (the present research site), need training to write formal reports in Chinese, the needs analysis result (conducted in August 2018) clearly responded negatively. As there is neither a report nor a book written on motivations and identities in learning United Nations official languages by United Nations staff members, this paper is a timely contribution not only to the concerns of the United Nations Secretariat, New York, but also to an understanding of the fields of language learning motivations and language leaning identities for adult learners.

\subsection{Recommendations for Future Research}

It would be advisable if the future study is conducted in an institutional setting with its staff members as a new sample to draw a much wider-reaching implications to the field of general language learning motivation and general language learning identity. In addition, a large majority or 68 percent of the United Nations staff members under study claimed that they learned Chinese more for functional and practical purposes, thereby displaying instrumental motivations (e.g., salary increases, bonuses, asking for directions, asking the time and taking a taxi) and less for workplace and office requirements (e.g., Chinese for meetings and Chinese for diplomacy). According to the first dataset (needs analysis results), it is suggested that the individual motivation level is higher than the institutional motivation level. By contrast, slightly more than half or 54 percent of United Nations staff members investigated contend that they have a good mix of motivations to learn Chinese for both personal and professional purposes and which involve both individual and organizational identities. This is suggested by the second dataset (qualitative survey results). There is clearly a difference between these two datasets. A future research project should make clear what causes the difference with good explanations for why these differences occur.

It appears that some heritage learners researched accept that their ethnic language is not necessary for maintaining their ethnic Chinese/Chinese Thai identity, probably because they identify themselves as mainstream Thais. A future research project should make clear whether Chinese heritage learners are willing to learn or re-learn their ethnic language, when given opportunities through a good Chinese language education program. A future research project should also make clear what causes some heritage learners who are strongly motivated to learn Chinese in comparison to others with the same ethnic Chinese background. 
Moreover, the present study's sample population consisted only of United Nations staff members at the beginning levels of UN Chinese level 1-2 (UN Chinese level 2 is equivalent to standard HSK 1) due to not being able to access those from higher levels at UN Chinese level 3-7 adult learners. Thus, this undertaking lacks a sample of intermediate-advanced level Chinese learners. A future research project should include United Nations staff members who are at UN Chinese level 3-7 (UN Chinese level 7 is equivalent to standard HSK 5).

Furthermore, to ensure United Nations Chinese teachers to have a better understanding of motivations and identities for Chinese language learning by United Nations staff members, the UN needs to encourage the development of Chinese teacher action research and a comparative study of two-three or more of different United Nations Chinese language programs at different UN headquarters and offices.

\section{References}

Arabski, J. \& Wojtaszek, A. (eds.) (2011). Aspects of culture in second language acquisition and foreign language learning. Berlin: Springer-Verlag Berlin Heidelberg, https://doi.org/10.1007/978-3-642-20201-8

Block, D. (2007). Second language identities. London/New York: Continuum

Cho, B.S. (ed.) (2018). New methods in applied language. New Rochelle, NY: Magnum Publishing LLC.

Clarke, A. (2005). Situational analysis: Grounded theory after the postmodern turn. London: Sage. https://doi.org/10.4135/9781412985833

David, M. K., Dealwis, C. \& Alagappar, P. N. (2011). Ethnic identity in the Tamil community of Kuching. In D. Mukherjee \& M. K. David (Eds.), National language planning and language shifts in Malaysian minority communities, 43-57. Amsterdam: Amsterdam University Press. https://doi.org/10.1515/9789048513383-005

Dessler, G. (2018). Fundamentals of human resource management. New York: Pearson.

Dörnyei, Z. (2002). Teaching and researching motivation. Essex, England: Pearson Education Limited.

Gardner, R. C. (1985). Social psychology and second language learning: The role of attitude and motivation. London: Edward Arnold.

Gay, L. R. \& Airasian, P. (eds.) (2003). Educational research: Competencies for analysis and applications. Upper Saddle River, NJ: Pearson Education, Inc.

Genc, B. \& Bada, E. (2005). Culture in language learning and teaching. The Reading Matrix, 5(1), 73-84.

Glaser, B.G. \& Strauss, A. L. (1967). The discovery of grounded theory: Strategies for qualitative research. Chicago, IL: Aldine. https://doi.org/10.1097/00006199-196807000-00014

Hymes, D. (1977). Foundations in sociolinguistics: An ethnographic approach. London: Tavistock Publications.

Ibsen-Jensen, R., Tkadlec, J., Chatterjee, K. \& Nowak, M. A. (2018). Language acquisition with communication between learners. Journal of the Royal Society Interface, 15(140), 20180073. https://doi.org/10.1098/rsif.2018.0073

Kim, A. S. (eds.) (2018.) New trends in applied language learning. New Rochelle, NY: Magnum Publishing LLC.

Lee, H. Y-H. (2018). The effect of multicultural family structures on the language attitudes of children and adolescents. GEMA Online ${ }^{\circledR}$ Journal of Language Studies, 18(1), 122-139. https://doi.org/10.17576/gema-2018-1801-08

Lee, H, Y-H. (2016). English language learning in the margins: Toward a movement to help service-industry workers in Thailand. Theory and Practice in Language Studies, 6(4), 649-662. https://doi.org/10.17507/tpls.0604.01

Lee, H, Y.-H. (2014). Losing Chinese as the first language in Thailand. Asian Social Science, 10(6), 176-193. https://doi.org/10.5539/ass.v10n6p176

Lee, H, Y.-H. (2013). Bargirl style of language choice and shift: A tale from the land of smiles. Theory and Practice in Language Studies, 3(3), 411-422. https://doi.org/10.4304/tpls.3.3.411-422

Macket, A. (2014, June 26). Wanting it enough: Why motivation is the key to language learning. The Guardian. Retrieved from https://www.theguardian.com/education/2014/jun/26/motivation-key-language-learning

Merriam, S. B. (2009). Qualitative research: A guide to design and implementation. San Francisco, CA: Jossey-Bass/John Wiley \& Sons, Inc.

National University of Singapore. (2018). The Eighth CLS International Conference (CLaSIC 2018) [Pamphlet / 
Brochure]. Singapore: National University of Singapore.

Norton, B. (1995). Social identity, investment, and language learning. TESOL Quarterly, 29, 9-31. http://dx.doi.org/10.2307/3587803

Norton, B. (2013). Identity and language learning: Extending the conversation. Bristol, England: Multilingual Matters. https://doi.org/10.21832/9781783090563

Richard, A. (1976). Language learning through communication practice. ELT Documents, 76(3), 2- 14.

Sankar, L. V. (2011). The importance of ethnic identity when language shift occurs: A study of the Malaysian Iyers. In D. Mukherjee \& M. K. David (Eds.). National language planning and language shifts in Malaysian minority communities, 23-41. Amsterdam: Amsterdam University Press. https://doi.org/10.1515/9789048513383-004

Seven, M. A. (2007). Importance of communication in language teaching. Turkey: Atatürk University

Thanasoulas, D. (2001). The importance of teaching culture in the foreign language classroom. Retrieved from: http://radicalpedagogy.icaap.org/content/issue3_3/7-thanasoulas.html Google Scholar

United Nations, Secretariat, Language and communications programme at the Headquarters, 2018/ from the Under-Secretary-General for Management (28 December 2017), available from https://digitallibrary.un.org/record/1479531?ln=en

Wylie, L. (1985). Language learning and communication. The French Review, 58(6), 777-785. 